\title{
COHESION, GENE FLOW, AND THE NATURE OF SPECIES*
}

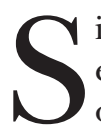
ince the Modern Synthesis, the view that species are cohesive entities held together by gene flow has moved from being a theoretical insight amongst systematists to common knowledge amongst biologists. The plant biologist Vern Grant provides a classic and succinct expression of this view, hereafter simply The View, in saying that "species populations are homogenized and integrated by gene flow." As one of us has recently detailed, several biologists have challenged the empirical adequacy of The View over the past forty odd years. ${ }^{2}$ Nevertheless, most biologists, including many phylogeneticists, have thought that species are cohesive entities, and the idea that gene flow is the primary cause of this cohesion continues to hold sway. ${ }^{3}$

The View offers a certain kind of explanatory cascade, which we articulate in the next section. Largely unrecognized by both critics

* The authors would like to thank audiences at the 2006 meetings of the Western Canadian Philosophical Association and the Philosophy of Science Association, both in Vancouver, for their constructive feedback on earlier versions of this paper and related work, as well as the Social Sciences and Humanities Research Council of Canada for financial support. For important comments, the first author is grateful to John Basl, Malcolm Forster, Rémy Petit, Alex Rueger, Larry Shapiro, Joel Velasco and members of the DC History and Philosophy of Biology reading group. The second author would like to acknowledge the work of Allison Dawe as a research assistant in the mid-1990s, which first got him puzzled about the topic of the paper. Both authors thank Ingo Brigandt and Elliott Sober for written comments that have led to improvements.

${ }^{1}$ Grant, "Gene Flow and the Homogeneity of Species Populations," Biologisches Zentralblatt, xcIX (1980): 157-69.

${ }^{2}$ Matthew J. Barker, "The Empirical Inadequacy of Species Cohesion by Gene Flow," Philosophy of Science, LXxiv (2008): 654-65. The classic critique is Paul Ehrlich and Peter Raven, "Differentiation of Populations," Science, CLXv (1969): 1228-32; reprinted in Marc Ereshefsky, ed., The Units of Evolution: Essays on the Nature of Species (Cambridge: MIT, 1991), pp. 57-67. See also John Endler, "Gene Flow and Population Differentiation," Science, CLXXIX (1973): 243-50, and, more recently, papers in Ulf Dieckmann, Michael Doebeli, John A. J. Metz, and Diethard Tautz, eds., Adaptive Speciation (New York: Cambridge, 2004).

${ }^{3}$ For phylogeneticists on this view, see Ed Wiley, Phylogenetics: The Theory and Practice of Phylogenetic Systematics (New York: Wiley, 1981); Wiley and Daniel R. Brooks, "Victims of History: A Nonequilibrium Approach to Evolution," Systematic Zoology, xxxi (1982): 1-24; and, more recently, Kevin de Queiroz, "A Unified Concept of Species and Its Consequences for the Future of Taxonomy," Proceedings of the California Academy of Sciences, LVI (2005): 196-215. For broader influence in evolutionary biology, see Niles Eldredge, "Species, Selection, and Paterson's Concept of the Specific-Mate Recognition System," in D. Lambert and H. Spencer, eds., Speciation and the Recognition Concept: Theory and Applications (Baltimore, MD: Johns Hopkins, 1995); Michael Ghiselin, Metaphysics and the Origin of Species (Albany: SUNY, 1997); and Loren H. Rieseberg, Troy E. Wood and Eric J. Baack, "The Nature of Plant Species," Nature, CDXL (2006): 524-27. 
and advocates of The View is a set of conceptual problems facing this explanatory cascade, problems that originate in often unexamined and shorthand talk of "gene flow" and "species cohesion." These problems become apparent once one draws a distinction between two kinds of cohesion. We view these problems as sufficiently serious to reject The View. Given the wide acceptance of the view within both the biological sciences and the philosophy of biology, this critique, if successful, is significant in itself. But it also provides a new perspective on at least four issues concerning species, each of which we will discuss in conclusion: (a) the study of species and evolutionary forces, (b) the taxonomically central yet notoriously vague notion of evolutionary unit, (c) related ontological claims about species individuality, and (d) pluralism about species concepts.

\section{SPECIES COHESION AND GENE FLOW}

Many biologists think species are distinctively cohesive entities that are marked off, in this respect, from other Linnaean taxa, such as genera or families. The View offers a causal explanation of this cohesion, and of the distinctive ontological status of species. Its essential posit is that gene flow explains species cohesion because gene flow is the primary cause of species cohesion.

The evolutionary genomicists Carrie Morjan and Loren Rieseberg have recently elaborated this view in typical fashion: "The traditional view is that species evolve as cohesive units held together by gene flow, which acts to prevent populations from differentiating through local adaptation or genetic drift." ${ }^{4}$ Gene flow is thought to be the primary preventer of such population differentiation largely in virtue of transmitting the crucial causes of development: genes. By spreading adaptive genes or washing out the effects of maladaptive ones, gene flow promotes phenotypic similarity among conspecifics. Consequently, conspecific organisms manifest a sort of evolutionary unity or cohesion as they trace a distinct trajectory through the space of evolutionary pressures, including selection and drift. As the ornithologist and systematist Ernst Mayr put it earlier, "[t]he stabilizing effect of gene flow is best documented by phenotypic uniformity," such that "[t]he steady and high genetic input caused by gene flow is the main factor responsible for cohesion among the populations of a species."

\footnotetext{
${ }^{4}$ Morjan and Rieseberg, "How Species Evolve Collectively: Implications of Gene Flow and Selection for the Spread of Advantageous Alleles," Molecular Ecology, XIII (2004): $1341-56$.

${ }^{5}$ Mayr, Animal Species and Evolution (Cambridge: Harvard, 1963), pp. 521-22.
} 
Most biologists understand gene flow essentially to involve transmission of genes from one population to another. Measures of migration from one population to another are then sometimes said to be gene flow. But when careful, authors note that migration measures are indirect indicators of gene flow. ${ }^{6}$ Migration of individuals (or simply of genetic material) from one population to another is necessary for gene flow, but not sufficient. Such migration must also leave a lasting phenotypic or genotypic footprint in the new population, modifying the population's trait frequencies. This is because the very point of talking of gene flow is to explain the process whereby populations (paradigmatically, within a species) come to resemble one another and to distinguish themselves from others. ${ }^{7}$

A further clarification is that although gene flow is defined interpopulationally, it typically occurs partly in virtue of, and thus implies, a more basic form of gene flow, one that occurs within populations as well. This is the intergenerational transmission of genes, from parent to offspring. Population biologists seldom focus on this more basic gene transmission. But species theorists rest at least implicitly on it when advancing The View. For multiple groups of organisms to manifest species cohesion, it is not sufficient that gene flow connects each group serially or even in more reticulate fashion. Each group must also itself be cohesive. And in implying that each group is cohesive in any putative case of species cohesion by gene flow, the advocate of The View appeals to more basic intergenerational gene transmission. Because this transmission is mediated by gene replication processes, token genes do not literally flow from one population to and through other populations, nor through generations, but copies do. For this reason, except in special cases, such as some cases of lateral gene transfer, the frequently used term "genetic exchange" can be misleading when used as a gloss on gene flow.

We can now offer a concise expression of The View that reveals the core of its explanatory structure. Species are cohesive entities in virtue of a common evolutionary trajectory that their members share because of the similarities they possess with respect to their underlying phenotypic and genotypic properties. These similar or shared properties exist within a given species because there is gene flow between its

\footnotetext{
${ }^{6}$ For two examples of such care, see Joseph E. Neigel, "A Comparison of Alternative Strategies for Estimating Gene Flow from Genetic Markers," Annual Review of Ecology and Systematics, xxviII (1997): 105-28; Michael E. Hellberg, Ronald S. Burton, Neigel, and Stephen R. Palumbi, "Genetic Assessment of Connectivity Among Marine Populations," Bulletin of Marine Science, Lxx (Supp. Vol.) (2002): 273-90.

${ }^{7}$ See Peter J. Beurton, "How is a Species Kept Together?," Biology E Philosophy, x (1995): 181-96.
} 
populations, the effects of which spread within those populations by intergenerational gene transmission. Gene flow thus triggers the following causal and explanatory cascade:

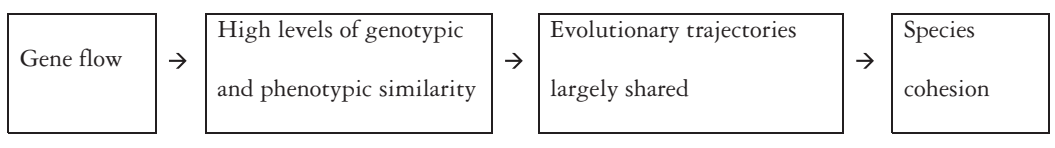

Figure 1: Species Cohesion by Gene Flow

Gene flow within a species thus makes that species an integrated whole, a closed gene pool within which genes flow but beyond which they do not, a unit whose parts have shared characteristics and that face evolutionary pressures as one.

To raise problems for this picture, let us now explore a distinction between types of cohesion.

\section{TWO TYPES OF COHESION ${ }^{8}$}

To say that species members share a common evolutionary trajectory in virtue of sharing underlying phenotypic and genotypic properties is to attribute what we call response cohesion to species. This is the property an entity has when its components respond (or are disposed to respond) as a unit to some kind of intervention. When the cells on my skin respond to a long day in the hot Australian sun by turning first brown and then red, they show response cohesion. For an entity to have response cohesion there need not be any significant or relevant causal interaction between its component parts. For example, individuals who have the electricity cut to their neighborhood could all respond in the same way (for example, lighting candles, calling the electricity company), and their response as a whole could be causally responsible for bringing about certain effects (for example, the restoration of power). The neighborhood would then display response cohesion, independent of any causal interaction between the individuals in it.

By contrast, an entity has integrative cohesion just if there are causal interactions between many or all of its components that facilitate their causal unification into a whole. Although an organism's skin cells can have response cohesion (as in the sunburn example), they also possess this further form of cohesion, as do many parts of the body.

\footnotetext{
${ }^{8}$ Compare the distinctions briefly drawn by Brent Mishler and Robert Brandon, "Individuality, Pluralism, and the Phylogenetic Species Concept," Biology Ẽ Philosophy, II (1987): 397-414, and by Marc Ereshefsky "Discussion: Axiomatics and Individuality: A Reply to Williams' 'Species are Individuals'," Philosophy of Science, LV (1988): 427-34.
} 
Bodies are made up, in part, of functional systems, such as the digestive and respiratory systems, and the causal interactions between the components of such systems - from organs right through to cells and their components - often result in higher levels of integration and unity. It is such unity and integration, so caused, that we mean by "integrative cohesion."

Groups of individuals can also possess integrative cohesion. For example, were the individuals in the neighborhood in the previous example to meet, communicate, and make plans together that they then jointly enacted (for example, to protest against the electricity company in some way), they would manifest integrative cohesion. The mechanisms underpinning this instance of integrative cohesion would be linguistic, social, and cultural in nature; in the case of the functional systems in an individual's body, they are anatomical and physiological. But as the first iteration of the neighborhood example showed, an entity can have response cohesion without integrative cohesion. Conversely, it can have integrative cohesion without related response cohesion. My bodily systems form a whole with integrative cohesion, as we noted, but the distinct functional natures of these systems do not always produce a uniform response to interventions, such as a temperature increase.

Even short of the more exhaustive exploration of this distinction that could be given, advocates of The View clearly imply that species often have integrative cohesion, not just response cohesion. As we have seen Grant express The View, "species populations are homogenized and integrated by gene flow" (op. cit., our emphasis). When Mayr says that "species have a reality and an internal genetic cohesion owing to the historically evolved genetic program that is shared by all members of the species," invoking the common metaphor of a species as a "protected gene pool," he is again appealing to what we are calling integrative cohesion. ${ }^{9}$ Ed Wiley and Daniel Brooks clearly have integrative cohesion, not (or not just) response cohesion, in mind when they claim that "[w]e may view the actual reproductive interactions within a species as a linkage pattern or network." ${ }^{10}$ Likewise, so does Michael Ghiselin when he writes that "[e]volution is possible at the population level. But we need to restrict ourselves to a particular kind of population, namely a whole integrated by sexual reproduction."11

\footnotetext{
${ }^{9}$ Mayr, Populations, Species, and Evolution (Cambridge: Harvard, 1970). The quotations are from p. 12 and p. 13, respectively.

${ }^{10}$ Wiley and Brooks, op. cit., at p. 6.

${ }^{11}$ Ghieslin, "Species Concepts, Individuality, and Objectivity," Biology E ${ }^{2}$ Philosophy, II (1987): 127-43, at p. 136.
} 
And David Hull carefully notes that the idea is that species have the same kind of integration as organisms: "Most organisms do exhibit more internal organization than most species, but this difference is one of degree, not kind."12

In light of this discussion, we could redraw Figure 1 as follows to clarify what The View says in terms of the distinction between integrative and response cohesion:

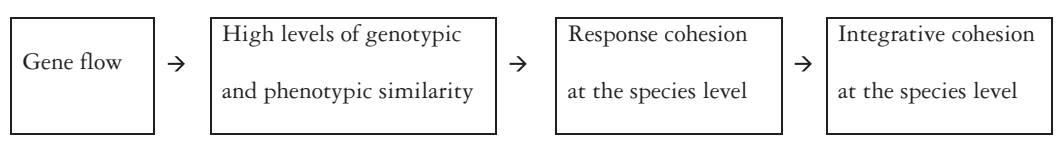

Figure 2: Integrative Species Cohesion by Gene Flow

All this suggests that proponents of The View are committed to two claims:

(1) The phenomenon that stands in need of explanation is integrative species cohesion.

(2) What explains integrative species cohesion, ultimately, is gene flow via its causal influence on the response cohesion of the species population.

We shall argue next that both of these claims are false.

\section{INTEGRATIVE COHESION AND PROBLEMS FOR THE VIEW'S EXPLANANDUM}

Consider two related problems with (1). The first of these stems from what is present between most conspecific populations and organisms: gaps. Species are typically made up of multiple and diffusely scattered populations that are separated by geographical (for example, mountains, oceans), climatic (for example, recurrent winds, temperature differences), behavioral (for example, preferences for local mating grounds) and ecological (for example, locale-specific niche differences) barriers. This marks a contrast between the vast majority of species and the neighborhood example, as well as more commonplace examples of integratively cohesive entities (for example, ordinary physical objects). As the above neighborhood example implies, groups of individuals can have integrative cohesion, but the gappiness of a typical species will preclude its being "group enough" to have that property.

The second and deeper problem for (1) stems from what is absent between conspecific populations and organisms: the appropriate

\footnotetext{
${ }^{12}$ Hull, "On the Plurality of Species: Questioning the Party Line," in Robert A. Wilson, ed., Species: New Interdisciplinary Essays (Cambridge: MIT, 1999), pp. 23-38, at p. 32.
} 
causal relations between parts. When an entity has integrative cohesion there are certain kinds of causal relations between the parts of that entity that, in part, explain its behavior or the effects brought about through its agency. This is what makes such entities integrated, as opposed to being simply cohesive: the cohesion of the whole is a function of the causal (or other) relations between the parts. The second problem is that conspecific populations do not bear these sorts of relations to one another. It is not just that the relations are there but are too weak to generate integrative cohesion. Rather, the gappiness typical of species - their organism and population "parts" being separated by mountains, oceans, currents, niche and behavioral differences, and so on-prevents even serial causal interactions between most or all species members. Since it is just such causal interactions between most or all species members that would make for integrative cohesion, species typically lack integrative cohesion.

Gappiness itself need not preclude the sorts of interactions required for integrative cohesion. Consider that the U.S.A. is similarly gappy (with many spatiotemporal obstacles between Alaska, Hawaii, and the lower forty-eight states), but relevant integrating relations between its parts still exist. Whether gappiness dampens or even precludes integration is a contingent matter. But as biologists now know, the behavioral and ecological traits of organisms in many species ensure that even modest intraspecific gaps are sufficient to preclude gene flow between conspecific populations (Barker, op. cit.). Hence the second problem for (1): that species are not integratively cohesive.

A natural response here is to think that these objections rest on too ham-fisted an interpretation of species cohesion, one that attributes to The View the claim that species are cohesive in just the sense in which (say) a solid material object, or a socially active neighborhood, is cohesive. Surely there is a broader, or perhaps weakened, sense in which species are integratively cohesive, it might be suggested. Yet the burden of proof is clearly on a proponent of The View to make out this response by moving beyond loose talk of species cohesion, while heeding the distinction between response and integrative cohesion. However, attempts to do this face a dilemma, depending on just how one moves from integrative cohesion as we have defined it. One could move quite radically, in effect seeking to rearticulate The View solely in terms of response cohesion. Or one might attempt to soften or weaken the notion of integrative cohesion itself. We will argue that versions of The View revamped in either of these ways are not defensible, at least not as versions of The View.

Suppose that one took the explanandum of The View to be response cohesion, that is, in this context, largely shared evolutionary trajectories. 
This is indeed consistent with many of the claims that biologists make about species when not explicitly discussing or defending The View. An example is Alan Templeton's "fundamental assumption" that it is best to study species cohesion by "examining the evolutionary forces operating on individuals within populations or subpopulations and tracing their effects upward until they ultimately cause all of the members of that population or subpopulation to acquire phenotypic attributes conferring species status on the group."13 However, reducing species cohesion to response cohesion substantially alters The View as it is explicitly defended and deployed, as can be seen by glancing back to the quotations we have provided from Grant, Mayr, Morjan and Rieseberg, Ghiselin, Hull, and Wiley and Brooks. It also leaves The View little if any reason for distinguishing gene flow from other possible explanantia of species cohesion, as we shall see in more detail in the next section.

To take the other horn of the dilemma, consider a weakened form of integrative cohesion that begins by noting that parts of a lineage stand in a diachronic, serial relation in which gene flow through the lineage plays an integrating role over time. It does this insofar as it generates genotypic and phenotypic similarity, and thereby promotes shared evolutionary trajectories among the lineage parts. So genes need only flow during enough brief intervals in the temporally extended entity that constitutes the species to generate and maintain this integration. Spatiotemporal unity is not required for integrative cohesion, so understood (and so the first problem is avoided); and relations like gene flow need not be constant and all-pervasive in order to generate this kind of integrative cohesion (and so the second problem is avoided).

It may be that, with further conceptual work, an appropriately weakened notion of integrative cohesion can be articulated along these lines in service of The View. But we have two grounds for doubt.

The first is that integrative cohesion weakened in this way is likely to be a property that is also shared by higher taxa. Given that all (or many) species descend from a common ancestor, and that this is certainly true for species within a clade, there has been some kind of gene flow, traced backwards in time, between populations of distinct species. If species have weakened integrative cohesion due to such gene flow, then so too do many higher taxonomic ranks. Indeed, emergence of new taxa and cases of interspecific hybridization ensure many populations of distinct species are more recently and/or frequently

\footnotetext{
${ }^{13}$ Templeton, "The Meaning of Species and Speciation: A Genetic Perspective," in David Otte and John A. Endler, eds., Speciation and Its Consequences (Sunderland, MA: Sinauer, 1989), pp. ??-??; reprinted in Ereshefsky, ed., op. cit., pp. 159-83, at p. 159.
} 
connected by gene flow than are many conspecific populations. If we keep in mind that The View has typically purported to identify integrative cohesion as a distinctive feature of species amongst other taxonomic ranks, then the weakening considered here grinds against the broader picture of species painted by The View.

The second is that, unlike the general characterization of integrative cohesion that we have provided, this weakened form of it characterizes that notion in terms of gene flow. But then integrative cohesion cannot be explained by gene flow, because the two are not distinct. Unless there is an articulation of this weakened form of integrative species cohesion that is independent of the appeal to gene flow, The View will suffer from a version of the classic problem identified by Molière in his satirical jibe at contemporary medicine's appeal to the dormitive powers of sleeping potions as an explanation of why such potions put one to sleep. ${ }^{14}$

While we have not tried to show that there is no notion of species cohesion fit for the job required by The View, we have argued that (a) species are not integratively cohesive (as we define it), and (b) attempts to respond to this claim by arguing that species are cohesive in some other sense face an initial dilemma, both horns of which are sharp. (1), which articulates the explanandum of The View, should be rejected.

\section{RESPONSE COHESION AND PROBLEMS FOR THE VIEW'S EXPLANANS}

Consider now (2), the idea that gene flow ultimately explains a species' integrative cohesion via its causal influence on the response cohesion of its populations. There are problems for (2) that concern the putative causal influence of gene flow on the response cohesion of species, and so we can consider them independently of the abovementioned problems with the putative integrative cohesion of species. As a preliminary, consider for a moment not gene flow, but simply genes. At least part of the appeal of the very first stage in the causal model postulated in The View (and depicted in Figures 1 and 2) is the idea that genes are causes of phenotypical characters, and so genotypes of phenotypes. Genes are uncontroversially such causes in the

\footnotetext{
${ }^{14}$ Could one respond here by claiming that gene flow realizes and thereby explains weak forms of integrative cohesion in species, in something like the way salt's microstructure putatively realizes and thereby explains its solubility? We think not. Gene flow explains species cohesion and evolutionary trajectories of species to the extent that it causes the conspecific similarities that underwrite trajectory sharing. If while doing this gene flow also realizes a weak form of integrative cohesion in species, this seems explanatorily irrelevant next to its role in causing conspecific similarity: the realized weak integrative cohesion would be epiphenomenal with respect to the phenomena of interest.
} 
sense that they are $a$ cause of phenotypic expression. Yet it is much more controversial whether they are some kind of privileged or unique such cause that marks them out either developmentally or evolutionarily. ${ }^{15}$ This familiar debate parallels a debate concerning the role of gene flow in generating genotypic and phenotypic similarity.

The core problem with (2) is that, upon clarifying the concept of species cohesion, there seems no justification for discriminating against other causes of a species' response cohesion in the way that (2) does. While gene flow can cause genotypic and phenotypic similarity in populations, it is seldom if ever such a cause in and of itself. As population biologists have only begun in recent years to thoroughly appreciate, developmental homeostasis, ecological regimes, various types of canalization, mutation, history, and the various forms that natural selection takes are also such causes. These factors play both contributory and counter-balancing roles to the causal role that gene flow plays in establishing and maintaining species cohesion. The line of reasoning encapsulated in Figures 1 and 2, however, implies that gene flow, like the gene itself, is a privileged cause or "main factor" (as we saw it put by Mayr) in the dynamic process that produces and sustains species cohesion. The question is whether there is some defensible basis for so identifying gene flow. Empirical and conceptual considerations suggest there is not. To see this, first consider two recent discussions by biologists that appeal to alternative or additional causes of response cohesion.

In a paper on the "implications of gene flow and selection" for "how species evolve collectively" that we have already drawn on, Morjan and Rieseberg (op. cit., p. 1341) imply that natural selection is often an important cause of response cohesion in species. They focus specifically on how "interactions of gene flow with selection" (ibid., p. 1342) can generate or sustain such cohesion. For example, when there is strong "selection for globally advantageous mutations," selection "controls the rate of spread of advantageous alleles" (ibid., p. 1342); these mutations can spread rapidly across populations, and so they and the selective forces that promote them "allow species to evolve as a cohesive unit, even for those populations connected with very low levels of gene flow" (ibid., p. 1342). Indeed, in such cases there is a sense in which low levels of gene flow, and selection, and mutations seem crucial causal factors of species cohesion. Traditional population genetic theory often overlooks such cases because it tends

\footnotetext{
${ }^{15}$ Susan Oyama, Paul Griffiths, and R. Gray, eds., Cycles of Contingency: Developmental Systems and Evolution. (Cambridge: MIT, 2001).
} 
to focus on "weakly selected mutations" (ibid., p. 1343), rather than strongly selected ones. But Morjan and Rieseberg point out that this "contrasts with the wealth of empirical evidence" (ibid., p. 1343) for adaptation by strong selection. And they note that at least some wellknown models of population dynamics suggest that "the strength of selection has a far greater effect on the rate of spread of advantageous mutations across subdivided populations" than does gene flow (ibid., p. 1342) ${ }^{16}$ Although Morjan and Rieseberg are proponents of The View and intend their article to show the efficacy of even low rates of gene flow, ironically their argument for this conclusion demonstrates the power that selection, in concert with other factors such as gene flow, has in generating response cohesion in species.

The Hellberg group's review of "connectivity among marine populations" (op. cit., p. 273) helpfully discusses alternative causes of species cohesion. As with Morjan and Rieseberg, these authors emphasize that "[s]elective sweeps...or stabilizing selection (where the same selected genotypes are favored over a wide range) could enforce homogeneity," and that, as a result, it can be misleading to presume that homogeneity implies significant gene flow (ibid., p. 276). But the authors emphasize other factors as well, including mutation, drift, and history (ibid., pp. 275-77). Consider history. Recolonizing populations take up a location in which the previous local population went extinct, and they tend to be genetically similar to their parent population. This similarity is often retained when there is little gene flow into or out of the recolonizing population after recolonization. Hellberg and his colleagues note that this similarity can be "misleading" (ibid., p. 277) in cases where selection plays a significant role in maintaining similarity over time. As they put it, "species with limited dispersal potential will carry the mark of history for a longer period of time than broad dispersers. Consequently, genetic approaches will tend to overestimate gene flow between recolonized populations and their sources" (ibid., p. 277). In short, certain types of historical events can be significant causes of response cohesion in species, and current methods can miss this because they are associated with a theory that presumes gene flow is the primary cause.

Given causes of response cohesion other than gene flow, how can a proponent of The View identify gene flow as causally, and so explana-

\footnotetext{
${ }^{16}$ For examples of the well-known models of population genetics alluded to, see Montgomery Slatkin's "The Rate of Spread of an Advantageous Allele in a Subdivided Population," in S. Karlin and E. Nevo, eds., Population Genetics and Ecology (New York: Academic Press, 1976), pp. ??-?, and his "Gene Flow and the Geographical Structure of Natural Populations,” Science, cCXxxvi (1987): 787-92.
} 
torily, privileged ${ }^{17}$ One might view gene flow as the means through which all other causes generate response (and thus integrative) cohesion. This would be to view gene flow as a kind of causal bottleneck through which other causes must pass if they are to generate integrative cohesion, much as Richard Dawkins has argued that genes are both developmental and evolutionary bottlenecks for evolutionary stasis and change. ${ }^{18}$ We can depict this by modifying Figure 2 with gene flow conceived as a mediating common cause of species cohesion:

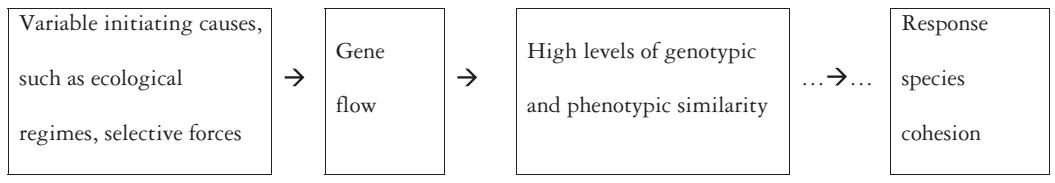

Figure 3: Gene Flow as a Mediating Common Cause of Species Cohesion

If Figure 3 captures the relationship between gene flow and other factors that produce species cohesion, however, then it is very hard to see a defensible rationale for privileging gene flow causally and explanatorily, as (2) requires. Even supposing that gene flow is a genuine bottleneck, something that empirical studies give us reason to doubt, high levels of genotypic and phenotypic similarity is a further such bottleneck, and one "closer" to species cohesion itself. If we privilege gene flow over putative initiating causes because it is a mediating common cause of species cohesion, then we should also privilege genotypic and phenotypic similarity over gene flow. Conversely, if we view gene flow as privileged over high levels of genotypic and phenotypic similarity in explaining species cohesion because it is what causes that similarity, then, likewise, we should also privilege whatever initiating cause there was of gene flow, over gene flow itself. In effect, this first option for privileging gene flow leads to another unsavory dilemma.

A second privileging option is to take gene flow not as a mediating common cause but as the initiating cause in the chain that leads

\footnotetext{
${ }^{17}$ Such privileging can be quantitatively or qualitatively based. There are prima facie problems with both. For example, how do you quantitatively compare the causal contributions corresponding to selection coefficients that attach to traits, with measurements of migration between populations? Proponents of The View tend to offer a qualitative basis for their privileging of gene flow. For example, Morjan and Rieseberg highlight gene flow's quality of playing a distinctive "creative role" (op. cit., p. 1343) in generating species cohesion. Unfortunately, the sense in which gene flow is said to play a distinctively creative role is not clear. We cast doubt on the conceptual assumptions underlying such qualitative privileging options.

${ }^{18}$ Dawkins, The Selfish Gene (New York: Oxford, 1989, $2^{\text {nd }}$ edition).
} 
eventually to species cohesion via diverse mediating causes, such as developmental homeostasis and other forms of canalization:

\begin{tabular}{|c|c|c|c|c|c|c|}
\hline $\begin{array}{l}\text { Gene } \\
\text { flow }\end{array}$ & $\rightarrow$ & $\begin{array}{l}\text { Mediating causes, such as } \\
\text { developmental homeostasis } \\
\text { and canalization }\end{array}$ & $\rightarrow$ & $\begin{array}{l}\text { High levels of genotypic } \\
\text { and phenotypic similarity }\end{array}$ & $\ldots \rightarrow \ldots$ & $\begin{array}{l}\text { Response } \\
\text { species } \\
\text { cohesion }\end{array}$ \\
\hline
\end{tabular}

Figure 4: Gene Flow as an Initiating Cause of Species Cohesion

In Figure 4, gene flow is what "kicks off" a causal process that leads (eventually) to species cohesion. The problem here is that even if gene flow does sometimes play such an initiating causal role, on The View it also clearly develops in response to just the kinds of mediating causes listed in Figure 4. To capture this, the causal arrow from gene flow to "downstream" mediating causes needs to be bidirectional. For although gene flow might causally influence developmental homeostasis, this homeostasis also causally restricts the set of organisms that can reproduce and (thereby) realize gene flow.

In fact, by integrating both suggestions thus far considered, we arrive at a more plausible view of how gene flow fits into the causal nexus, one that takes us even further from (2):

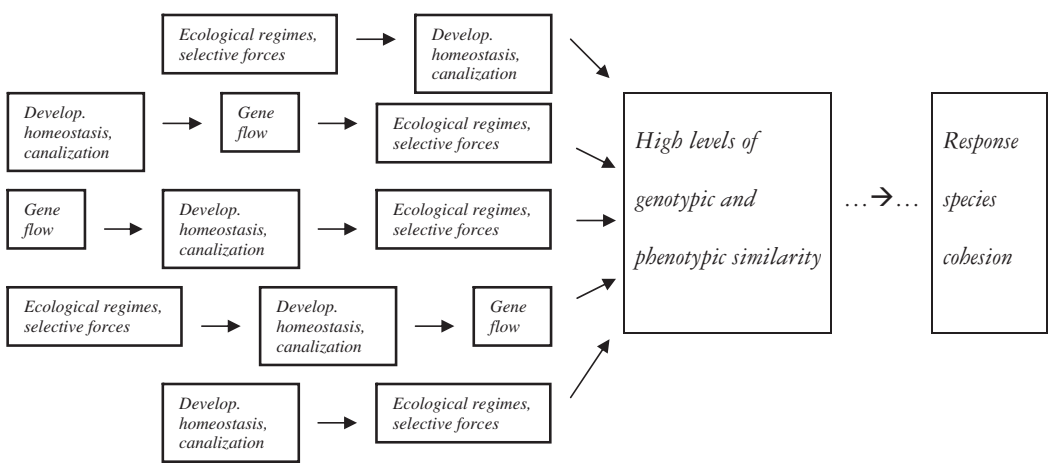

Figure 5: Gene Flow in the Causal Nexus

We believe that Figure 5 provides a more theoretically appropriate and empirically adequate framework within which to think about the causes of species cohesion. Thus, the privileging of gene flow in (2) cannot be justified.

Might one concede that while gene flow is not a privileged cause of species cohesion, nonetheless, a lack of gene flow explains why species 
are different from each other? This alternative explanandum is logically related to the one we have been discussing in a way that rules out this option. To see this, consider an empirical example that has helped show that gene flow is insufficient for species cohesion. Genes have, as Templeton notes (op. cit., p. 166), flowed at significant rates between balsam poplars and cottonwoods for hundreds of thousand of years. Yet those species remain distinct because each has faced different selection and ecological regimes. Thus, lack of gene flow between species cannot be necessary for those species to each have cohesion of their own: gene flow's being insufficient for a possible (broader) instance of species cohesion entails that lack of gene flow is not necessary for distinct (narrower) instances of cohesion. To move from this point about necessity, back to explanation: the prevalence of interspecific hybridization in nature suggests that lack of gene flow is not a privileged or general explanation (for example, one that fails only in special cases) of distinct instances of species response cohesion.

In this and the previous section we have used a distinction between integrative and response cohesion to articulate two problematic claims that advocates of The View make regarding species cohesion. The first is that the explanandum that stands in need of explanation is species' integrative cohesion. This claim is problematic because multipopulational species are spatiotemporally gappy in a way that inhibits the causal relations between conspecifics required for integrative cohesion. The second claim is that gene flow explains the integrative cohesion of species in virtue of its special causal influence on response cohesion. This is problematic because attempts to accommodate the recognition of the plurality of causes of response cohesion call into question the explanatory cascade at the heart of The View that privileges gene flow. For these reasons, we advocate rejection of The View.

\section{BROADER IMPLICATIONS FOR STUDYING AND THINKING}

\section{ABOUT SPECIES}

Finally, we turn to four implications of our discussion. Here we constructively suggest ways in which moving beyond The View, and drawing explicitly on the distinction between response and integrative cohesion, may lead to a richer future understanding of species, gene flow, and cohesion.

V.1. Evolutionary Forces. In their discussion of the "connectivity among marine populations" that we drew on above, Hellberg and his colleagues have two broad goals: to illuminate the complexity of evolving marine populations and to offer prescriptions for dealing with this complexity. In meeting the first of these goals, they show how new DNA sequencing methodologies suggest that populations 
are (a) more dynamic, (b) less stable and (c) subject to more complexly interacting evolutionary forces (for example, drift, gene flow, mutation, selection, and history) than population geneticists-such as themselves-have previously thought. As a result, old theoretical models and assumptions need to be updated, new methodologies developed, and greater interdisciplinary collaboration fostered. For instance, Hellberg's group notes that selection and history are especially difficult causes of species cohesion to study and thus "future genetic surveys should include more detailed spatial and temporal sampling and employ analyses of DNA sequence data that can reveal the signatures of natural selection and historical changes" (op. cit., p. 273). Such methodologies will require population geneticists, ecologists, and phylogeneticists of various sorts to work more closely than they have, with the hope being that richer patterns of explanation emerge.

Our discussion strengthens these sorts of prescriptions, especially by bringing conceptual clarity to (c) through the distinction between integrative and response cohesion. This, in turn, motivates new and more integrated methodologies, explanatory patterns, and disciplinary relationships that better capture the complexities we highlighted. Reconceiving the role of gene flow in creating and maintaining species cohesion along the lines suggested by Figure 5 is part of what is needed here. But it is also now clear that we need a richer set of conceptual tools for thinking about the complex interactions between various causes and how to measure their effects. One way in which philosophers might further contribute here is to tease apart the epistemic from the metaphysical challenges that complicate attempts to study evolutionary forces. ${ }^{19}$

V.2. Species as Evolutionary Units. Consider now the popular ideas that species are "evolutionary units" and have a reality that higher taxa lack. ${ }^{20}$ The first idea's popularity is unsurprising in light of the influence of the view that species are cohesive: species are evolutionary units in that they have cohesion. And the distinctive ontological status of species sub-species taxa amongst Linnaean taxa is even presupposed by phylogeneticists who wish to abandon, except for species, the Linnaean hierarchy in favor of the rank-free Phylocode. ${ }^{21}$ This is

\footnotetext{
${ }^{19}$ The notion of entwinement introduced in the context of the levels of selection may prove useful here. See Wilson, "Pluralism, Entwinement, and the Levels of Selection," Philosophy of Science, LXX (2003): 531-52, and his Genes and the Agents of Life: The Individual in the Fragile Sciences: Biology (New York: Cambridge, 2005), chapter 10.

${ }^{20}$ For example, see Ereshefsky, "Species, Higher Taxa, and the Units of Evolution," Philosophy of Science, LVIII (1991): 84-101; Hull, "Are Species Really Individuals?," Systematic Zoology, xxv (1976): 174-91.

${ }^{21}$ A good example of such a phylogeneticist is de Queiroz, op. cit.
} 
primarily because they think that higher Linnaean taxa lack the cohesion, the evolutionary unity, that species display.

However, despite its popularity, "evolutionary unit" has remained notoriously vague. We think this is partially because of inadequate attention to species cohesion. Rightly, some authors have recently demanded that "evolutionary unit" be clarified and its putative role in taxonomic views subsequently justified..$^{22}$ Our discussion of species cohesion begins providing clarification. It suggests that the evolutionary unity of a typical species consists in response cohesion, not integrative cohesion. More precisely, to be an evolutionary unit is to be an entity that has response cohesion with respect to evolutionary pressures such as selection, drift, and migration, that is, to be composed of parts or members that respond, or are disposed to respond, as a unit to selection, drift, migration, and so on. This leaves open the possibility (which other facts may or may not close off) that taxa other than species are evolutionary units: nothing in their nature rules out their having response cohesion with respect to evolutionary pressures. Of course, response cohesion comes in degrees or grades. But this may explain away the common idea that taxa above the rank of species are not evolutionary units: those taxa often have response cohesion with respect to evolutionary pressures, but to a lesser degree than do species. Taxa below the species rank, such as demes, may have a higher degree or grade of this response cohesion. Importantly, these points alone do not license the claim that higher taxa are unreal or less real. This is a further issue, and we see no prima facie reason to think differences in degree or grade of response cohesion are ontologically decisive here.

A related issue, perhaps of more taxonomic interest, is whether taxonomists choose arbitrarily when choosing which of the real differences between grades of response cohesion are the ones that mark distinctions between ranks. Even if these choices are largely arbitrary, species may be one of many sorts of taxa that have real response cohesion with respect to evolutionary pressures. The distinctness of species in particular - their nature - consists in part (and only in part) in having a particular degree or grade of such cohesion.

V.3. Species Ontology. These initial clarifications of "evolutionary unit" throw light on the related ontological thesis that species are individuals. Hull's influential version of this thesis implied that species are individuals, in a "strict" sense of that term, because they are evolutionary

${ }^{22}$ Joel Velasco makes this demand persuasively in Philosophy and the Tree of Life: The Metaphysics and Epistemology of Phylogenetic Systematics (Ph.D. Dissertation: University of Wisconsin, Madison, 2008). 
units. ${ }^{23}$ His contrast was a weaker notion of individuality that even spatially discontinuous nations such as the U.S.A. can satisfy. Minimal and distinguishing requirements for individuality in the strict sense are unity and continuity (ibid., p. 93) and, according to Hull, "[s]pecies as evolutionary units fulfill the strict requirements. They are "individuals' in the same sense that organisms are individuals" (ibid., p. 93). Despite this view's popularity, some authors have found it too strong. ${ }^{24}$ We can now put this worry simply and forcefully. For $X$ to be an individual in the strict sense is at least in part for it to be in $X$ 's nature to have integrative cohesion. Indeed, if we use paradigm individuals such as organisms as our guide, individuality requires integrative cohesion of a high degree. In any case, Hull's thesis is false because species typically do not have integrative cohesion. And when they do, this is contingent, not in their nature: it is a property they could lose while remaining species. Perhaps a particular degree or grade of response cohesion characterizes species as evolutionary units. Yet this is insufficient for individuality (in Hull's strict sense).

These comments are compatible with the softening of the individuality thesis that is sometimes expressed by saying that species are "historical entities." But this idea cries out for metaphysical development. We think it is best developed as part of the homeostatic property cluster (HPC) view of natural kinds. ${ }^{25}$ We will not dwell on this claim here, except to bring out one feature of the HPC view that our discussion highlights.

The HPC view implies that apparently disjunctive properties (including historical, reproductive and other relational properties) that define kinds of entities are often coinstantiated. Shared causal mechanisms underwrite their coinstantiation and because of this they form definitive property clusters that are homeostatic. Individuative and explanatory practices in numerous scientific disciplines motivate this suggestion. The rejection of (2), and so The View, in favor of a

\footnotetext{
${ }^{23}$ Hull, "The Ontological Status of Species as Evolutionary Units," in R.E. Butts and J. Hintikka, eds., Foundational Problems in the Special Sciences (Boston: Reidel, 1977), pp. 91-102.

${ }^{24}$ Examples are Kim Sterelny, "The Nature of Species," Philosophical Books, xxxv (1994): 9-20, and Wilson, "Realism, Essence, and Kind: Resuscitating Species Essentialism?," in Wilson, ed., op. cit.

${ }^{25}$ For different expressions of the view that species are HPC kinds, see Richard Boyd, "Homeostasis, Species, and Higher Taxa," in Wilson, ed., op. cit., and in the same volume, Griffith's "Squaring the Circle: Natural Kinds with Historical Essences," and Wilson's "Realism, Essence, and Kind: Resuscitating Species Essentialism?" For a recent discussion that responds to some critiques of the HPC view, see Wilson, Barker, and Ingo Brigandt, "When Traditional Essentialism Fails: Biological Natural Kinds," Philosophical Topics in press.
} 
more complex view of the way in which gene flow, properly understood, can lead eventually to response cohesion in species supports (and is supported by) the HPC view of natural kinds. Conspecific populations are responsively cohesive, and the nexus of causal factors, including gene flow, that create and sustain that cohesion makes these populations very much like the natural kinds articulated by the HPC view. (Indeed, one might simply identify some such populations with species taxa.)

V.4. The Species Problem. Finally, consider the classic problem of defining "species," beginning with the biological species concept (BSC). All reproductive definitions of "species" are variations on the BSC, which holds that species are "groups of interbreeding natural populations that are reproductively isolated from other such groups." Immediately after this restatement of the BSC, Mayr says that a "species is a protected gene pool ... a Mendelian population that has it own devices (called isolating mechanisms) to protect it from harmful gene flow from other gene pools" (ibid., p. 13). Given this, it would be natural to paraphrase "interbreeding natural populations" as "populations between which there is gene flow." Yet there is a problem with this way of conceptualizing what a species is that is readily expressible in terms of response and integrative cohesion.

Species of organism are characterized by a degree or grade of response cohesion, and it is when this response cohesion breaks down radically, for some reason, that we change the number of species. Either there is a speciation event (more accurately, perhaps, a process), an extinction event, or a blending of distinct species. Some species may have, in addition, a contingent and weakened sort of integrative cohesion, and some subset of those species have such integrative cohesion in virtue of gene flow between their constituent populations. But gene flow is simply one mechanism amongst many for generating both response and (if and where it exists) integrative cohesion; it should not be the only part of the definition of what a species is. In effect, this is one way to motivate both liberalizations of (for example, Templeton's cohesion species concept) and alternatives to (for example, Wiley's evolutionary species concept) the BSC. Although we have no allegiance to any of these, we can end by gesturing in a direction that the abovementioned HPC view opens up.

Aficionados of recent discussions of "the species problem" may point out that our distinction between response and integrative cohesion, and our discussion of the many causes of cohesion, fits nicely

${ }^{26}$ Mayr, Populations, Species, and Evolution (Cambridge: Harvard, 1970), at p. 12. 
with pluralism about species concepts. Pluralists such as John Dupré and Philip Kitcher see the many different species concepts that compete in the literature, and the many causes of species cohesion that in part underwrite this variety, as evidence for there being no unified species category. ${ }^{27}$ On such views, "species" is an ambiguous term that refers to different kinds of things, studied by different branches of biology. But alternatively, if response cohesion in species and the complex causal nexus that gives rise to it supports something like an HPC kind individuated by causally related mechanisms - such as gene flow, selection, and history - then there is reason for hypothesizing that the species category is an HPC kind rather than a disjunction of wholly distinct kinds. Being a species may partly involve being held together by the mechanistically coinstantiated causes of response species cohesion we have discussed. This would motivate synthesis of pluralistic and monistic views of species, but we leave further pursuit of that suggestion for another time.

University of Wisconsin, Madison

MATTHEW J. BARKER

ROBERT A. WILSON

University of Alberta

${ }^{27}$ For Dupré's pluralism, see his The Disorder of Things: Metaphysical Foundations of the Disunity of Science (Cambridge: Harvard, 1993); for Kitcher's, see “Species," Philosophy of Science, LI (1984): 308-33. 